\title{
Human activities predominate in determining changing incidence of tick-borne encephalitis in Europe
}

S E Randolph (sarah.randolph@zoo.ox.ac.uk) ${ }^{1}$, on behalf of the EDEN-TBD sub-project team ${ }^{2}$

1. Department of Zoology, University of Oxford, South Parks Road, Oxford OX1 3PS, United Kingdom

2. The members of the team are listed at the end of the article

Randolph SE, on behalf of the EDEN-TBD sub-project team. Human activities predominate in determining changing incidence of tick-borne encephalitis in Europe. Euro Surveill. 2010;15(27):pii=19606. Available online: http://www.eurosurveillance.org/ViewArticle.aspx?Articleld=19606

Explanations for the dynamics of tick-borne disease systems usually focus on changes in the transmission potential in natural enzootic cycles. These are undoubtedly important, but recent analyses reveal that they may not be quantitatively the most significant side of the interaction between infected ticks and humans. Variation in human activities that may impact inadvertently but positively on both the enzootic cycles and the degree of human exposure to those cycles, provide more robust explanations for recent upsurges in tick-borne encephalitis in Europe. This can account for long-term increases in incidence that coincided with post-soviet political independence, for small-scales spatial variation in incidence within a country, and for short-scale fluctuations such as annual spikes in incidence. The patterns of relevant human activities, typically those related to the use of forest resources, are evidently driven and/or constrained by the cultural and socio-economic circumstances of each population, resulting in contrasting national epidemiological outcomes.

\section{Introduction}

The incidence of infection with vector-borne zoonoses is inherently dynamic in space and time because transmission cycles depend on interactions between pathogens, arthropod vectors and vertebrate hosts, many of which are responsive to changing environmental conditions. Furthermore, the risk of human infection varies not only with the abundance of infected vectors, but also with the amount of human exposure to that hazard, either one of which may change independently. The relative contributions of these various factors can be dissected for one of the most significant vector-borne diseases in Europe, tick-borne encephalitis (TBE), because of the reliable long-term records and a well-quantified understanding of the underlying biology, ecology and human risk factors [1-5] (and see below). One obvious environmental change concerns the climate, which has been much debated in the past and will not form part of this review that is focused specifically on socio-economic determinants. Furthermore, hitherto, a convincing explanation for an increase in enzootic transmission potential to match an observed upsurge in TBE cases has been found only in some parts of western Europe and does not involve climate change. In north-east Italy, land and wildlife management practices have improved habitat suitability for rodents, the transmission hosts for the TBE flavivirus, and for enhanced populations of deer, the most important host for the vector, the tick Ixodes ricinus [6], concomitant with a steady increase in TBE cases over the past decade. In Sweden, prior to the first doubling in TBE incidence in 1984 an epidemic of sarcoptic mange had knocked the fox population down, allowing a sharp increase in numbers of deer as predation on fawns was reduced $[7,8]$. Although causality has not been tested, this could have resulted in increased tick densities, as tick abundance and tick-borne disease incidence are correlated temporally and spatially with deer densities $[9,10]$. This, however, accounts for neither the second doubling in Sweden in $\mathbf{2 0 0 0}$, nor the continuing steady increase since the disease became notifiable there in 2004 .

In most central and eastern European (CEE) countries, where TBE has been a notifiable disease since at least the 1970 [11], national mean incidences increased between 2- and 30-fold abruptly in 1993, with marked heterogeneity in degree and timing at finer spatial scales. Within any one country, upsurges did not occur everywhere that the virus is known to circulate, but when they did the degree of increase varied by an order of magnitude and the timing of onset varied between 1990 and 1998 (see Figure 1 for an example from Slovakia).

No single factor is likely to cause such a pattern. Instead, a nexus of interacting, independent but synergistic, biotic, abiotic and socio-economic impacts on all four partners within the system (virus, vector, vertebrate wildlife and human) has been proposed and supported by comparative data from five diverse countries (Slovenia, Czech Republic and the three Baltic countries) [12-14]. The conclusion from analyses of extensive datasets on past and present events is that local human activities can and have shifted suddenly to alter the degree of contact between people and infected 
ticks, while human-induced environmental changes that may enhance enzootic cycles generally take effect more gradually. This is consistent at different time- and space-scales, from long-term political reorganisation, through small-scale changes in land use and ownership, to short-term responses to weather conditions. At each scale, socio-economic conditions and cultural practices appear to have driven and/or constrained the relevant human activities. The same ideas can be applied to the more gradual emergence of TBE in western Europe, but data on potential causal factors relating to humans have not yet been compiled and analysed to identify specific effects.

\section{Long-term impacts from political independence}

Political independence in CEE in the early 1990 s was unexpectedly accompanied by a dramatic upsurge in TBE incidence in most countries (Hungary and Croatia were notable exceptions). Detailed analyses of primary data have suggested a causal linkage [13] that can be summarised as follows: to varying degrees in each country, agricultural reorganisation left much arable land fallow and much grassland un-grazed, and therefore subject to gradual re-colonisation by natural vegetation suitable for rodents and ticks. At the same time, significantly reduced pesticide usage (documented for the Baltic countries and Slovenia [13]) and higher densities of deer in all countries may account for the marked increase in tick ( $/$. ricinus) abundance, as shown by rare long-term systematic records from a forest close to Riga, Latvia [13]. Alongside much reduced industrial activity, the reduced collective agricultural activity also contributed to an abrupt rise in unemployment, driving many people back to their small farmsteads for a more subsistence way of life on land closer to tick-infested forested areas and using virtually no pesticides; this could have brought them into closer contact with ticks. With the polarisation of society, measured by an increasing Gini coefficient (an index of household economic inequality), other fractions of the populations benefited from increased wealth in

\section{FIGURE 1}

Annual numbers of tick-borne encephalitis cases since 1970 in all Slovakia (inset) and each kraj (region), showing the typical spatial and temporal heterogeneity in incidence within one country

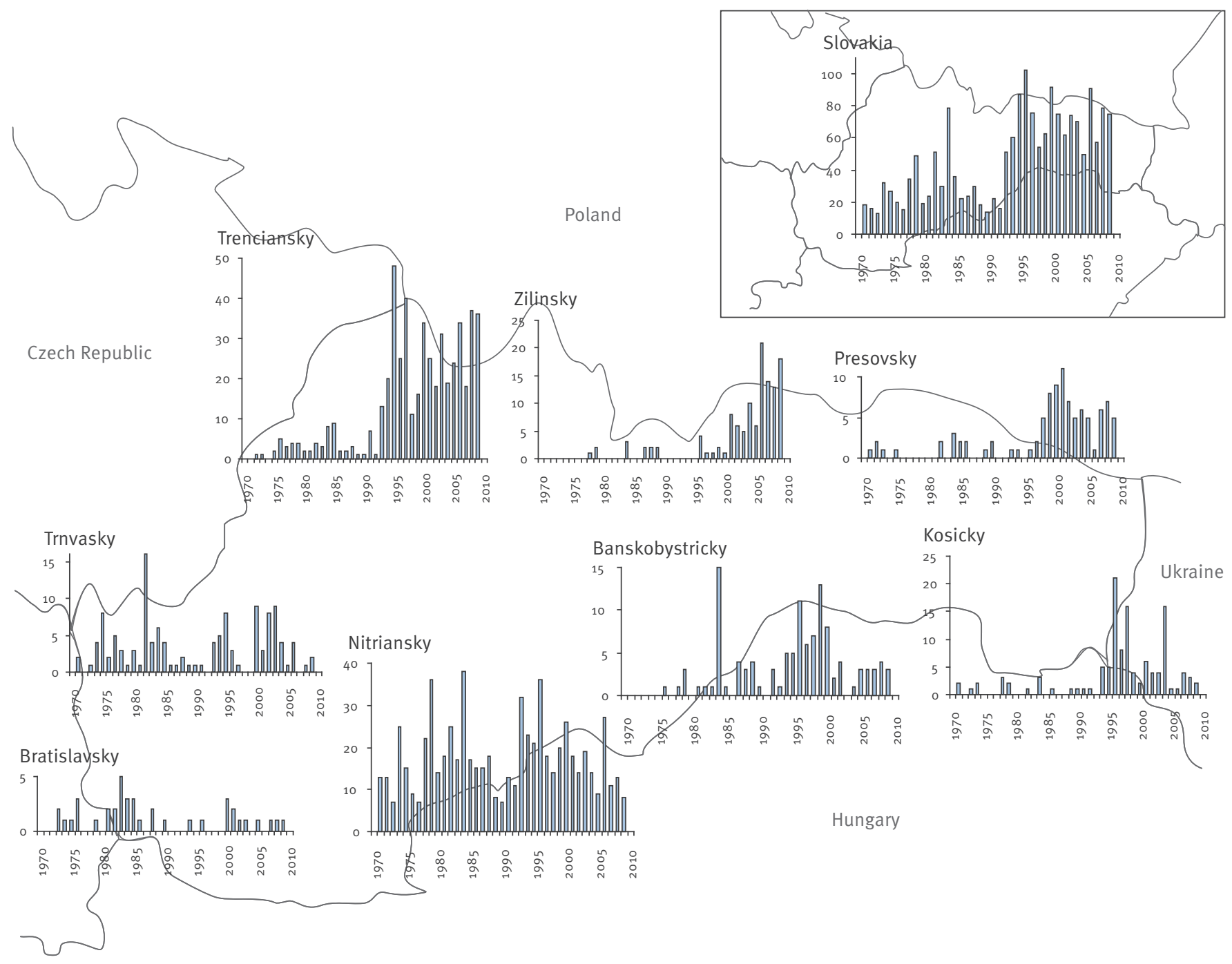

Source: Public Health Authority of the Slovak Republic. 
the new market economy. The traditional practice of harvesting berries and mushrooms from forests was enforced both by poverty, when this free food necessarily augmented family diets, and by greater wealth, leisure time and individual travel. Furthermore, new markets for wild mushrooms opened up in western Europe, where city market stalls and delicatessens are now commonly supplied from Poland and Lithuania. Data from a survey in 2000 in Latvia [15] reveal that the activity of mushroom gathering is unfortunately, but not surprisingly, associated with a much higher risk of tick bite than is simple recreational use of forests [16]. With different democratisation processes during the early 1990s, the degree of socio-economic transition and its impact on human exposure to TBE virus evidently varied markedly between countries, with the Czech Republic amongst the least affected while Lithuania, Latvia and northeast Poland were hardest hit. This is reflected in a remarkable correlation between the degree of TBE upsurge (doubling in the Czech Republic, but 4- to 30-fold increases in the Baltic States) and the percentage of household expenditure spent on food across eight CEE countries $\left(R^{2}=0.716\right)$
[13], which suggests that activities related to the conditions of everyday life are a significant factor in TBE incidence.

As a potential alternative explanation, changes in public health activities, particularly those related to surveillance and diagnosis, could have caused an artificial increase in recorded TBE incidence. The impact of these activities on recorded incidence is difficult to assess, especially as surveillance practices vary between countries, there is no standardised case definition, and diagnostic protocols are improved periodically [11]. While these problems might reduce the precision of the quantitative associations described here, longterm familiarity with this infection amongst local medical practitioners confirmed by personal interviews, and detailed analyses of the timing of improved diagnosis relative to the geographically heterogeneous patterns of TBE upsurge, provide convincing evidence that much of the upsurge was real and not purely a product of public health changes [17]. After all, similar changes in public health practices also occurred in western Europe without causing such a massive abrupt

\section{FIGURE 2}

Numbers of Ixodes ricinus ticks (A) and numbers of people self-reporting tick bites (B), by 10-day period, Riga county, Latvia, January 2002-December 2003
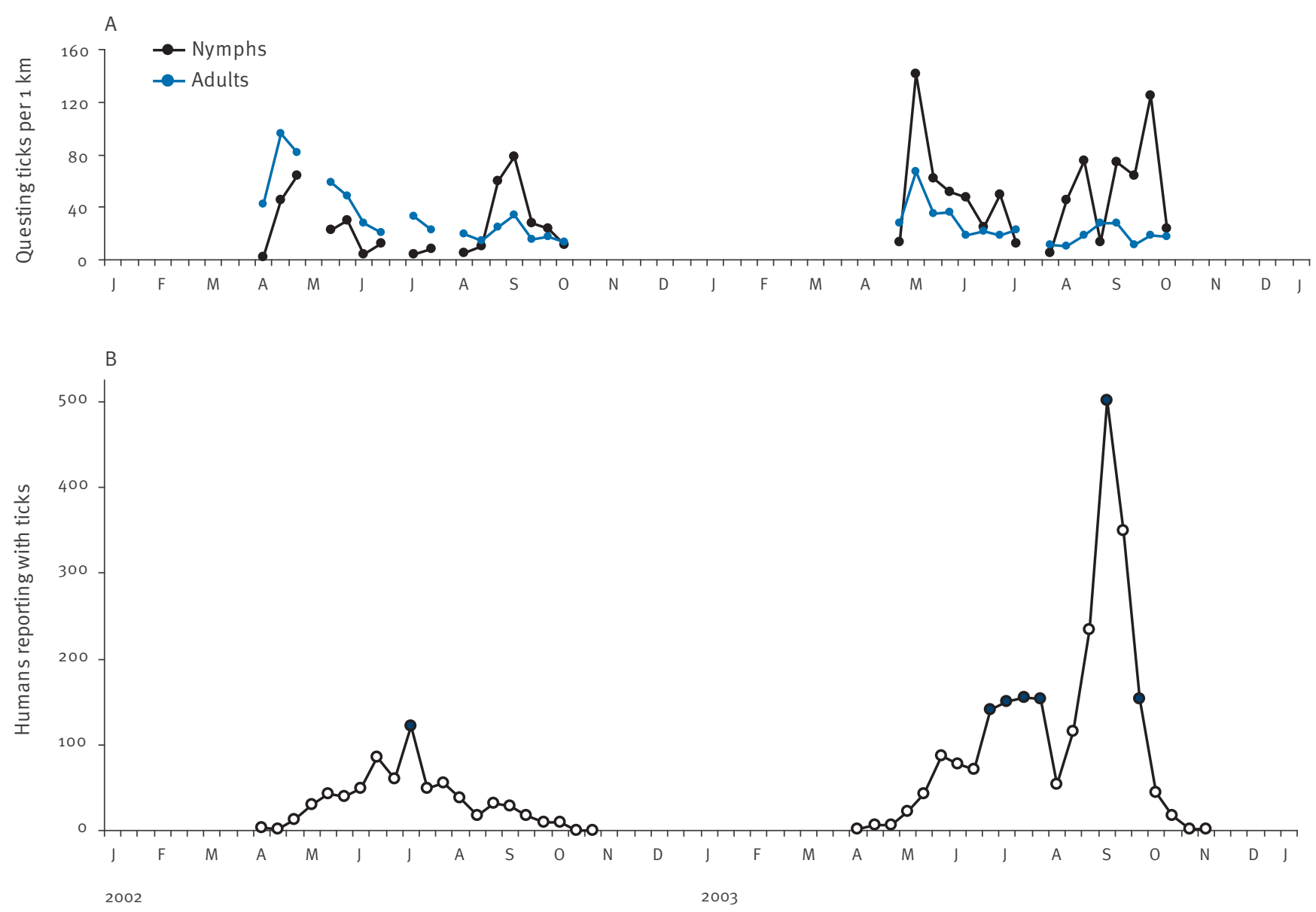

A. Ticks (nymphs: black; adults: blue) were counted by standardised flagging methods at the Tireli monitoring site.

B. Self-reporting of tick bites was to the State Public Health Agency in Riga. Dark blue dots mark periods that included rain-free weekends with mean maximum air temperatures above $150 \mathrm{C}$ and heavy rainfall in the preceding week.

Reproduced from [16]. 


\section{FIGURE 3}

Examples of contrasting patterns of the relative seasonal profiles of monthly TBE cases and questing nymphal ticks expressed as percentages of annual totals for the mean of 2000-2005, 2006 and 2007
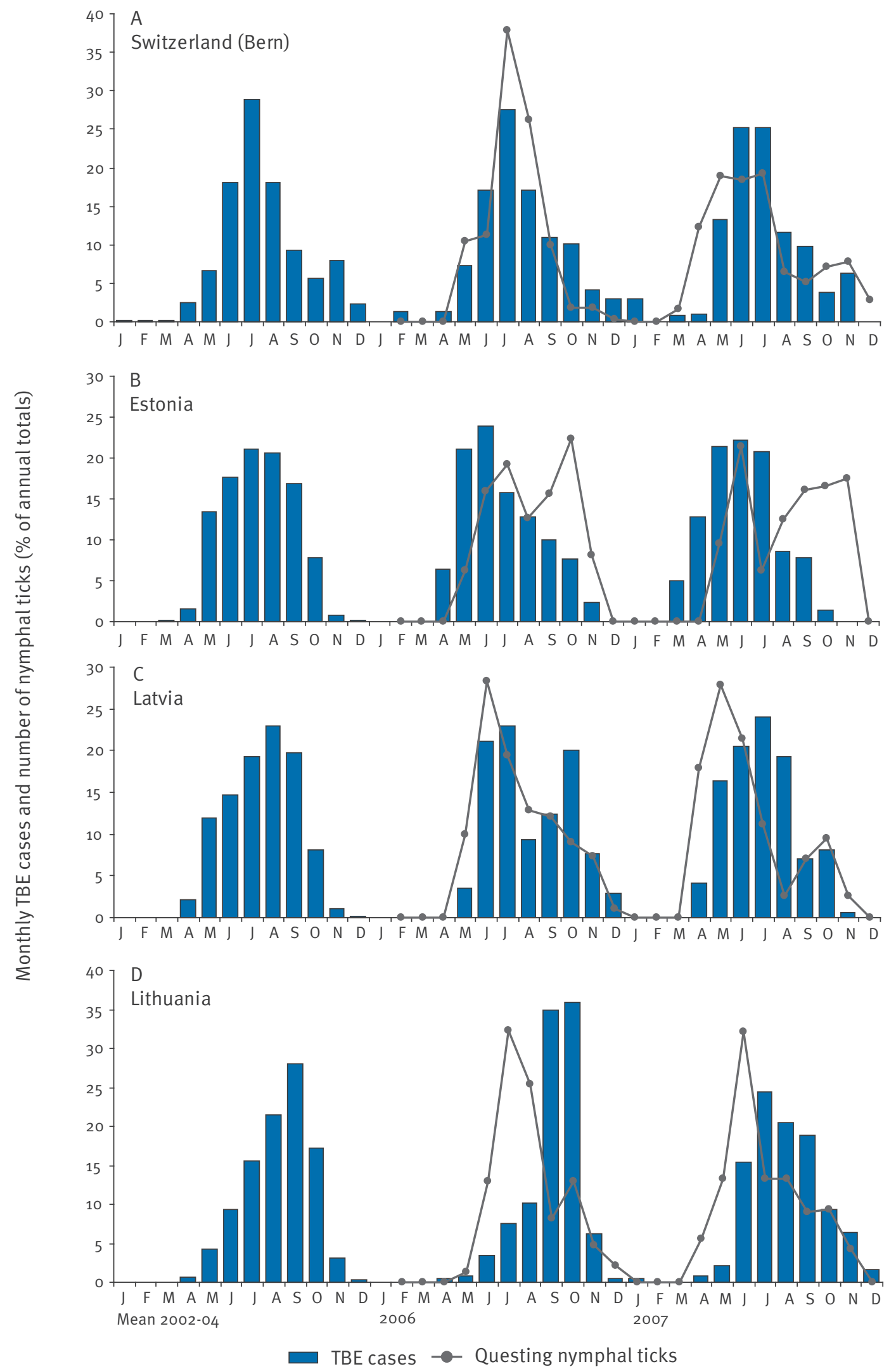

TBE: tick-borne encephalitis.

The tick data are lagged by one month to accommodate the average delay between tick bites and TBE reporting.

For information on tick monitoring sites, see [21]. 
upsurge. In no country does the date when TBE became a notifiable disease [11 and Table1 therein] coincide with any increase in incidence, apart from Sweden in 2004. Furthermore, some changes would be expected to reduce the incidence, particularly any campaign to promote self-protection through awareness and avoidance of risk, and the use of the highly effective anti-TBE vaccine [18]. Vaccination coverage did indeed increase in Slovenia and all three Baltic States from two years after the TBE upsurge, fluctuated thereafter in step with TBE incidence two years previously, and was highest in those Baltic counties that had the greatest TBE incidence [16]. These observations suggest a response to perceived risk. Moreover, TBE incidence in Latvia decreased markedly from 1999, but the degree of this decrease far exceeded that which could be explained by vaccination and was greatest where the previous incidence had been highest, again indicating human avoidance of ticks in response to perceived risk. The Latvian survey [15] reported a change in behaviour, with people going to forests less often after 1999 than before. Nevertheless, both vaccination and reduced use of high-risk forests were least common amongst the poorest sector of the population [16], pointing to an economic constraint. Finally, there was no correspondence between these epidemiological patterns and the presence of the second tick species, I. persulcatus, which occurs only in eastern Estonia and Latvia.

Hungary is an interesting case where there was no increase in TBE incidence in the early 1990s, but a sudden decline in TBE incidence in 1997, which may have been due to changes in public health services leading to under-reporting. Since that time, diagnosis has had to be paid for by the individual hospitals, and financial constraints mean that this is now requested only in the special situations of milk-borne outbreaks of TBE or where there are problems with differential diagnosis. As West Nile virus also circulates in Hungary, expensive virus neutralisation tests are needed to distinguish between this and TBE virus, while physicians gain little from an accurate diagnosis in their medical care of patients (limited to symptomatic treatment) (Emôke Ferenczi, personal communication, September 2009). Irrespective of any differential medical care, correct diagnosis is, of course, vital for establishing the epidemiology of these two infections.

\section{Small-scale impacts of land cover, land use and land tenure}

The significance of human activities constrained by socio-economic factors in driving the dynamics of TBE incidence, as inferred from the above gross-scaled epidemiological patterns, is also apparent from a finerscaled analysis within a single country. The spatially variable incidence of reported TBE cases from 1999 to 2003 in rural parishes (i.e. municipalities) in Latvia can best be explained and predicted by three aspects of landscape that include human as well as physical factors: land cover, that determines the suitability of the habitat for ticks and tick-host populations, land use, that determines whether the local human population is likely to enter the forest on a regular basis, and landownership, that determines how these two aspects may intersect through access rules [19]. In this analysis, land use (i.e. the purpose for which people enter forests) was inferred indirectly from socio-economic markers known from analysis of the Latvian survey data [15] to be associated principally with either recreational use of forests or collection of wild foods from forests [16]. Thus, although people in all socio-economic brackets visit forests regularly, those with lower income and lower education do so more frequently, and more commonly with the purpose of collecting wild food, in contrast to those in the middle and upper socio-economic classes who are more likely to visit the forest for recreation.

At the Latvian national scale, a multi-factorial negative binomial regression model, including the autocorrelated spatial factor of infection in neighbouring parishes, revealed a higher risk of TBE where a higher percentage of forest had been felled in 2000 (probably reflecting high exposure of forest workers), where a smaller percentage of the population had an economic activity and where more of each parish was occupied by state-owned forest to which the public has right of access [19]. Within the more homogenously rural northeastern region of Latvia, Vidzeme, a complementary range of similar predictor variables was identified: TBE risk was greater in parishes with more forest that had not been clear-cut, less cultivated land, proportionately fewer people with higher education, and proportionately more pensioners. Similar effects of forest clearance on tick abundance has been recorded for the Czech Republic, but persisting only for two years after clearing until regeneration of the natural vegetation restored favourable conditions for $I$. ricinus ticks [20].

Thus the evidence supports the intuitive expectation that the spatially variable risk of TBE within a small country is determined by a combination of landscape structure, much of it shaped by human agency, and people's socio-economic status that may direct the way they use tick-infested forests.

Short-term responses to weather conditions In addition to these inferences, more direct evidence for the importance of human activities in determining exposure to infection can be gleaned from short-term temporal patterns. One example comes from comparing regular records of questing tick abundance in the Tireli forest just outside Riga, Latvia with the numbers of tick bites reported to the Public Health Agency in Riga in the years 2002 and 2003 [16]. Within each annual tick activity season (spring to autumn), there was considerable variation in abundance of $/$. ricinus ticks recorded at 10 -day intervals (Figure $2 \mathrm{~A}$, reproduced from [16]). High tick numbers, however, were not matched by high numbers of reported tick bites. Rather, tick bites peaked on rain-free weekends with mean maximum air temperatures above $15^{\circ} \mathrm{C}$ following 
heavy rainfall during the preceding week (marked by dark blue dots in Figure $2 \mathrm{~B}$, reproduced from [16]). As mushrooms are thought to be most abundant after rainfall followed by warm weather, and as people prefer outdoor activity in dry weather, these mismatching temporal patterns suggest that exposure to tick bites is determined more by human foraging activities than tick questing activities.

Furthermore, against the background of longer-term shifts in TBE incidence, there are occasional sudden spikes in annual incidence, which must reflect the natural variability in environmental conditions for enzootic transmission and/or human exposure. The year 2006 was particularly valuable in throwing light on such short-term phenomena because unusually high spikes occurred in synchrony in several western and central European countries, and by great good fortune these spikes coincided with monthly sampling of ticks during the period 2006 to 2008 at a total of 81 sites in 13 countries across Europe as part of the EU-FP6 Emerging Diseases in a Changing European Environment (EDEN) project (http://www.eden-fp6project.net/). Detailed analyses of meteorological records (daily maximum temperature and precipitation), monthly numbers of I. ricinus nymphs and monthly cases of TBE for eight countries (Switzerland, Germany, Slovenia and the Czech Republic that showed exceptional spikes in 2006, north-east Poland and Lithuania where incidence was high in 2006 but not exceptionally so, and Estonia and Latvia that showed no change in 2006) revealed that the variable spikes in TBE case numbers were related to a specific combination of weather over 2006, but independent of variable tick abundance, suggesting that human responses to weather were more important [21]. In all these countries, but least marked in Estonia and Latvia, relative to other years in the period between 1970 and 2008, an unusually cold January to March 2006 was followed by unusually warm and dry July to December 2006, punctuated by a cold wet August, and warm January to June 2007. Ticks started their seasonal activity about one month earlier in the warm spring of 2007 compared with 2006, but the annual total number counted in 2007 was not consistently higher than in 2006 (higher only at 11 of the 41 sites), as expected if each new cohort of unfed ticks emerges after moulting only in the autumn [22]. More importantly, the spike of TBE cases in 2006 did not coincide consistently with a greater abundance of ticks in 2006 than in 2007 (more ticks at only eight of the 41 sites), nor was the earlier onset of tick activity in 2007 matched by more than a very small number of earlier cases of TBE that year.

All the evidence indicates that seasonal and annual patterns of TBE incidence are not simple reflections of tick abundance, but due in large part to changing human activity. The testable prediction, therefore, is that the degree of mismatch in the seasonal profiles of questing tick abundance and TBE incidence should vary according to cultural and socio-economic constraints, which is indeed observed (Figure 3).

Consistently from 2000 to 2007 , case numbers of TBE in Germany, Slovenia and Switzerland peaked between June and August, more or less matching the seasonal profile of tick abundance (lagged by one month to accommodate the delay between tick bites and TBE reporting), but with virtually no change in response to the earlier tick season in 2007 (Figure 3A, Switzerland shown as an example of a pattern consistent for these three countries). This suggests that TBE risk mirrors people's summer (recreational) outdoor activity, which, unfortunately, coincides with maximum seasonal tick challenge in these countries. Numbers of summer visitors to a major national park in Slovenia confirm the obvious supposition that $90 \%$ of such activity occurs between May and September, and is encouraged by unusually warm dry weather (in July, September, October, but not August, 2006) [21]. The situation in Estonia also points to human summer activity as the determinant of risk, as TBE cases decline after August even though tick activity persists more or less undiminished through September and October (Figure 3B). A different pattern is seen in the Czech Republic and Latvia, where high incidence of TBE persists later in the summer and autumn (exaggerated in 2006) after tick activity has declined markedly from its spring peak (Figure $3 \mathrm{C}$ ), which is thought to reflect disproportional exposure to ticks during the harvest of autumnal forest foods [23]. A differently skewed mismatch occurs in Lithuania and north-east Poland, where disproportionately few TBE cases occur before July when ticks are most abundant, as if people rarely enter forests at this time, but many more TBE cases occur after August, despite much reduced tick activity after midsummer (Figure 3D). Given the importance of mushrooms as an exported cash crop in these last two countries [24], it is reasonable to suppose that people may make additional efforts to secure a good harvest for their living when the crop is poor, with less potential for opportunistic recreational foragers to respond to good years. This could explain the sporadic autumnal spikes in TBE incidence rather than an exceptional spike in 2006. In summary, these extensive and intensive data all indicate that the spikes in TBE cases in 2006, and possibly other less dramatic fluctuations in incidence, were due to exceptional weather conditions affecting people's behaviour, which had a differential impact depending on socio-economic and cultural factors.

\section{Discussion}

Human activities of all sorts are commonly directed to a greater or lesser extent by geographically and temporally variable socio-economic constraints, with consequences for health (both non-communicable ill-health and directly transmitted infectious diseases) and reciprocal impacts of health on wealth, even within Europe [25-29]. For vector-borne zoonoses, human-induced environmental change (climatic, landscape, biotic) may affect the transmission potential of wildlife cycles, 
whereas human activities per se predominate in determining, and thereby potentially avoiding, contact with those cycles and so the risk of infection. This adds complexity and instability to the spatio-temporal dynamics of these disease systems. The analyses described here are based on correlational studies, which are by no means ideal for attributing causality to epidemiological patterns. They have, nevertheless, advanced our thinking significantly by identifying a range of new factors that need to be considered in future, more purpose-built, empirical studies. In the specific case of TBE in central and eastern Europe, many of the recent human-induced environmental changes originated in the socio-economic effects of political transition, and appear to have had an impact on the living conditions of all partners within this disease system - virus, ticks, wildlife and humans. Because of the biology of ticks as vectors, with their long generation time and slow pace of pathogen transmission due to the long interval between feeds, changes in transmission potential operate on a longer time scale than do changes in human exposure to infected ticks. The evidence presented in this review indicates that this latter effect can occur rapidly and thereafter may endure for variable periods, from a few months of extra recreation to many years of a new life-style. The fluidity with which people respond to new opportunities depends not only on current socioeconomic conditions but also on their cultural traditions and expectations. The traditional exploitation of forests for food, apparently expanded either for export or for private enterprise in local markets or to enhance diets out of necessity or pleasure, has been quantified as a major risk factor for TBE $[15,16]$. Greater wealth, leisure and consequent potential for outdoor recreation brings similar risks. As soon as more than one causal factor is introduced, each operating with differential force and eliciting variable human responses, a spatially and/or temporally heterogeneous outcome is to be expected. Although many of these conclusions arise from detailed analyses of data from the Baltic States, because of the quality of data available there, entirely consistent patterns are seen where comparable information has been examined for other countries, notably Slovenia and the Czech Republic. This is striking, because these latter countries fall at opposite ends of both the geographical range of CEE countries and the spectrum of socio-economic impacts of the political reform of the early 1990 s.

Elsewhere in Europe, where socio-economic conditions have been more stable (pace the recent economic crises), the more gradual emergence of TBE may prove to be due more to enhanced enzootic cycles. In northeast Italy, the geographically defined appearance of TBE over the past two decades has been attributed to changes in forest structure, specifically a decreased ratio of coppice to high stand forest that has improved habitat suitability for rodents and deer [6]. As these authors point out, these changes in land and wildlife management practices are part of a shift from the pre19th century concept of a forest as a wood-producer to the modern concept of a complex ecosystem highly connected with the territory where it is located, with cultural and aesthetic landscape values, and the functions of protecting hydrogeology, soil and biodiversity. Once again, human purposes, operating within a philosophy permitted by relative socio-economic wellbeing, are instrumental in driving TBE emergence.

\section{Acknowledgements}

It is a pleasure to acknowledge the invaluable contributions to the data collection underpinning this review made by all researchers within the tick-borne diseases sub-project of the EU-Fr6 EDEN project in addition to the formal partners named below. Dana Šumilo and Sophie Vanwambeke made particularly important contributions. This work was supported by the Wellcome Trust (grant no. 070696/Z/03/Z and Value in People award), the University of Oxford (Career Support Scheme) and EU grant GOCE-2003-010284 EDEN; it is catalogued by the EDEN Steering Committee as EDENo170 (http://www.eden-fp6project.net/). The contents are the sole responsibility of the authors and do not necessarily reflect the views of the European Commission.

EDEN-TBD sub-project team:

Pedro Anda, Centro Nacional de Microbiologia-Instituto de Salud Carlos III, Madrid, Spain;

Tatjana Avsic-Zupanc, Institute of Microbiology and Immunology, Faculty of Medicine, Ljubljana, Slovenia;

Antra Bormane, State Agency "Public Health Agency", Riga, Latvia;

László Egyed, Veterinary Medical Research Institute, Budapest, Hungary;

Emôke Ferenczi, “Johan Béla” National Centre for Epidemiology, Division of Virology, Budapest, Hungary;

Ana L. García-Pérez, NEIKER- Instituto Vasco de Investigación y Desarrollo Agrario, Derio, Spain;

Lise Gern, Institut de Biologie, Université de Neuchâtel, Switzerland; Zdenek Hu;balek, Institute of Vertebrate Biology, Academy of Sciences, Brno, Czech Republic;

Maria Kazimirova, Institute of Zoology, Slovak Academy of Sciences, Bratislava, Slovakia;

Maceij Kondrusik, Department of Infectious Diseases, Medical Academy, Bialystok, Poland;

Kurt Pfister, Department of Comparative Tropical Medicine and Parasitology, Ludwig Maximilian University, Munich, Germany;

Annapaola Rizzoli, Fondazione Edmund Mach, Istituto Agrario di San Michele All'adige, Trento, Italy;

Veera Vasilenko, National Institute for Health Development, Tallinn, Estonia;

Alexandru Vladimirescu, The National Institute of Research and Development for Microbiology and Immunology "Cantacuzino", Bucharest, Romania;

Milda Žygutiene, Centre for Communicable Diseases Prevention and Control, Vilnius, Lithuania.

\section{References}

1. Labuda M, Nuttall PA, Kozuch O, Elecková E, Williams T, Zuffová E, et al. Non-viraemic transmission of tick-borne encephalitis virus: a mechanism for arbovirus survival in nature. Experientia. 1993;49(9):802-5.

2. Labuda M, Randolph SE. Survival of tick-borne encephalitis virus: cellular basis and environmental determinants. Zentralbl Bakteriol. 1999;289(5-7):513-24.

3. Gritsun TS, Lashkevich VA, Gould EA. Tick-borne encephalitis. Antiviral Res. 2003;57(1-2):129-46.

4. Randolph SE, Green RM, Peacey MF, Rogers DJ. Seasonal synchrony: the key to tick-borne encephalitis foci identified by satellite data. Parasitology. 2000;121(Pt 1):15-23.

5. Nuttall PA, Labuda M. Tick-borne Encephalitis Subgroup. In: Sonenshine DE, Mather TN, editors. Ecological dynamics of tick-borne zoonoses. New York, Oxford: Oxford University Press; 1994. p.351-91.

6. Rizzoli A, Hauffe HC, Tagliapietra V, Neteler M, Rosà R. Forest structure and roe deer abundance predict tick-borne encephalitis risk in Italy. PLoS One. 2009;4(2):e4336. 
7. Lindström ER, Andrén H, Angelstam P, Cederlund G, Hörnfeldt $B$, Jäderberg L, et al. Disease reveals the predator: sarcoptic mange, red fox predation, and prey populations. Ecology. 1994;75(4):1042-9.

8. Davidson RK, Bornstein S, Handeland K. Long term study of Sarcoptes scabiei infection in Norwegian red foxes (Vulpes vulpes) indicating host/parasite adaptation. Vet Parasitol. 2008;156(3-4):277-83.

9. Jensen PM, Frandsen F. Temporal risk assessment for Lyme borreliosis in Denmark. Scand J Infect Dis. 2000;35(5):539-44.

10. Jensen PM, Hansen H, Frandsen F. Spatial risk assessment for Lyme borreliosis in Denmark. Scand J Infect Dis. 2000;32(5):545-50.

11. Donoso Mankte O, Schälder R, Niedrig M. A survey on cases of tick-borne encephalitis in European countries. Euro Surveill. 2008;13(17). pii: 18848. Available from: http://www. eurosurveillance.org/ViewArticle.aspx?Articleld=18848

12. Šumilo D, Asokliene L, Bormane A, Vasilenko V, Golovljova I, Randolph SE. Climate change cannot explain the upsurge of tick-borne encephalitis in the Baltics. PLoS One. 2007;2(6):e500.

13. Šumilo D, Bormane A, Asokliene L, Vasilenko V, Golovljova I, Avsic-Zupanc T, et al. Socio-economic factors in the differential upsurge of tick-borne encephalitis in Central and Eastern Europe. Rev Med Virol. 2008;18(2):81-95.

14. Randolph SE. Tick-borne encephalitis incidence in Central and Eastern Europe: consequences of political transition. Microbes Infect. 2008;10(3):209-16.

15. Marketing and Public Opinion Research Centre SKDS. [Investigation into the factors hindering immunisations of the population against diphtheria and tick-borne encephalitis]. Riga, Latvia: National Public Health Agency SKDS. Report. 2001; p.179. Latvian.

16. Šumilo D, Asokliene L, Avsic-Zupanc T, Bormane A, Vasilenko $\mathrm{V}$, Lucenko I, et al. Behavioural responses to perceived risk of tick-borne encephalitis: vaccination and avoidance in the Baltics and Slovenia. Vaccine. 2008;26(21):2580-8.

17. Šumilo D, Bormane A, Vasilenko V, Golovljova I, Asokliene L, Zygutiene M, et al. Upsurge of tick-borne encephalitis in the Baltic States at the time of political transition, independent of changes public health practices. Clin Microbiol Infect. 2009;15(1):75-80.

18. Heinz FX, Holzmann H, Essl A, Kundi M. Field effectiveness of vaccination against tick-borne encephalitis. Vaccine. 2007;25(43):7559-67.

19. Vanwambeke SO, Sumilo D, Bormane A, Lambin EF, Randolph SE. Landscape predictors of tick-borne encephalitis in Latvia: land cover, land use and land ownership. Vector Borne Zoon Dis. 2010;10(5):497-506.

20. Hubalek Z, Halouzka J, Juricova Z, Sikutova S, Rudolf I. Effect of forest clearing on the abundance of Ixodes ricinus ticks and the prevalence of Borrelia burgdorferi s.l. Med Vet Entomol. 2006;20(2):166-72.

21. Randolph SE, Asokliene L, Avsic-Zupanc T, Bormane A, Burri $C$, Gern L, et al. Variable spikes in TBE incidence in 2006 independent of variable tick abundance but related to weather. Parasit Vectors. 2008;1(1):44.

22. Randolph SE, Green RM, Hoodless AN, Peacey MF. An empirical quantitative framework for the seasonal population dynamics of the tick Ixodes ricinus. Int J Parasitol. 2002;32(8):979-89.

23. Daniel M, Kriz B, Danielova V, Benes C. Sudden increase in tick-borne encephalitis cases in the Czech Republic, 2006. Int J Med Microbiol. 2008;298(S1)(81-7).

24. Boa E. Wild edible fungi. A global overview of their use and importance to people. Rome: Food and Agriculture Organisation of the United Nations; 2004.

25. McKee M, Fister K. Post-communist transition and health in Europe. BMJ. 2004;329(7479):1355-6.

26. Stuckler D, King L, Coutts A. Understanding privatisation's impacts on health: lessons from the soviet experience. J Epidemiol Community Health. 2008;62(7):664.

27. Stuckler D, King LP, Basu S. International monetary fund programs and tuberculosis outcomes in post-communist countries. PLoS Med. 2008;5(7):e143.

28. Stuckler D, King L, McKee M. Mass privatisation and the postcommunist mortality crisis: a cross-national analysis. Lancet. 2009;373(9661):399-407.

29. McKee M, Suhrcke M, Nolte E, Lessof S, Figueras J, Duran A, et al. Health systems, health, and wealth: a European perspective. Lancet. 2009;373(9660):349-51. 